\title{
Differential unfolded protein response during Chikungunya and Sindbis virus infection: CHIKV nsP4 suppresses elF2a phosphorylation
}

\author{
Abhay P S Rathore ${ }^{1,2}$, Mah-Lee $\mathrm{Ng}^{2}$ and Subhash G Vasudevan ${ }^{1,2^{*}}$
}

\begin{abstract}
Chikungunya (CHIKV) and Sindbis (SINV) are arboviruses belonging to the alphavirus genus within the Togaviridae family. They cause frequent epidemics of febrile illness and long-term arthralgic sequelae that affect millions of people each year. Both viruses replicate prodigiously in infected patients and in vitro in mammalian cells, suggesting some level of control over the host cellular translational machinery that senses and appropriately directs the cell's fate through the unfolded protein response (UPR). The mammalian UPR involves BIP (or GRP78), the master sensor in the endoplasmic reticulum (ER) together with the three downstream effector branches: inositol-requiring ser/thr protein kinase/endonuclease (IRE-1), PKR-like ER resident kinase (PERK) and activating transcription factor 6 (ATF-6). Through careful analysis of CHIKV and SINV infections in cell culture we found that the former selectively activates ATF- 6 and IRE-1 branches of UPR and suppresses the PERK pathway. By separately expressing each of the CHIKV proteins as GFP-fusion proteins, we found that non-structural protein 4 (nsP4), which is a RNA-dependent-RNA polymerase, suppresses the serine-51 phosphorylation of eukaryotic translation initiation factor, alpha subunit (elF2a), which in turn regulates the PERK pathway. This study provides insight into a mechanism by which CHIKV replication responds to overcome the host UPR machinery.
\end{abstract}

\section{Introduction}

Chikungunya virus (CHIKV) is a member of the alphavirus genus, which contains 26 known arboviruses with a wide host range [1]. During the past 50 years, numerous CHIKV epidemics have been documented in both Africa and Asia [2]. Since, its discovery, CHIKV has spread widely and currently Chikungunya fever has been detected in nearly 40 countries with a potential to affect millions of people worldwide [3]. In general, alphaviruses are divided into viruses that cause human diseases characterized by rash and arthritis, that are primarily found in the "old world" such as CHIKV, O nyong nyong, Sindbis (SINV), Ross River, Barmah Forest and Mayaro virus [4] and viruses that cause encephalitis, which are primarily found in the "new world". The first clear association of an alphavirus with arthritic disease was made

\footnotetext{
* Correspondence: subhash.vasudevan@duke-nus.edu.sg

${ }^{1}$ Program in Emerging Infectious Diseases, Duke-NUS Graduate Medical School, 8-College Road, Singapore 169857, Singapore

${ }^{2}$ Department of Microbiology, National University of Singapore, Singapore 117597, Singapore
}

\section{Biomed Central}

c 2013 Rathore et al.; licensee BioMed Central Ltd. This is an Open Access article distributed under the terms of the Creative Commons Attribution License (http://creativecommons.org/licenses/by/2.0), which permits unrestricted use, distribution, and reproduction in any medium, provided the original work is properly cited. in 1953 when CHIKV was isolated from the blood of individuals in Tanzania with severe arthritis [5]. SINV was first isolated in 1952, which causes similar disease to CHIKV in humans known as sindbis fever and the symptoms include arthralgia, rash and malaise [6]. These arthritogenic alphaviruses share certain antigenic determinants [4] and also considerable genome similarity that makes them interesting for comparative responses to the host. In humans, CHIKV infection is characterized by a rapid onset of fever that is cleared in 5-7 days with long lasting immunity [7]. The major pathology associated with CHIKV infection is very high viremia and polyarthritis [8-11]. The mortality rate associated with CHIKV infection has been estimated to be 1:1000 with most deaths occurring in neonates, adults with underlying conditions and the elderly [3]. The persistent detection of viral RNA or antigen in the host has suggested the long-term persistence of these viruses in humans $[12,13]$. The alphavirus genome is a single-stranded RNA genome of $\sim 12 \mathrm{~kb}$ in size of positive polarity. It encodes two polyproteins of which the first encodes 
nonstructural proteins (nsPs) 1-4: nsP1 contains methyl transferase and guanyl transferase activities, nsP2 is a helicase/protease, nsP3 is an accessory protein involved in RNA synthesis and nsP4 is the RNA dependent RNA polymerase. The second polypeptide, translated from a subgenomic RNA codes for structural proteins, capsid (C) and the envelope glycoproteins, E1 and E2 that constitute the virion coat $[4,14,15]$. Several studies have shown that alphavirus replication in mammalian cells usually results in severe cytopathicity, mainly caused by dramatic shutdown of host translation machinery [16-20]. However, the mechanism by which CHIKV maintains such a high replication rate in the infected cells is poorly understood.

One host response mechanism that has the potential to limit virus replication is the endoplasmic reticulum (ER) stress response, also known as unfolded protein response (UPR) which, maintains cellular protein homeostasis and prevents the over-accumulation of unfolded proteins in the lumen of the ER during normal and diseased states [21]. ER chaperone immunoglobulin heavy chain binding protein (BIP), also known as glucose regulated protein 78 (GRP78) plays a central role in this process via a three-pronged regulatory pathway involving PKR-like ER kinases (PERK), activating transcription factor 6 (ATF-6) and the ER transmembrane protein kinase/endoribonuclease (IRE-1). Under stress conditions, BIP is sequestered to misfolded or unfolded proteins in the ER whereupon it activates PERK, ATF-6 and IRE-1 [22]. During UPR, PERK activates by selfdimerization and phosphorylation. Activated PERK phosphorylates eIF $2 \alpha$ at serine-51 and leads to an inhibition of general protein synthesis. PERK activation also induces the activation of C/EBP homologous protein ( $\mathrm{CHOP}$ ) and growth arrest and DNA damage-inducible protein GADD34 [23]. CHOP is responsible for apoptosis mediated cell death when functions of ER are severely impaired to protect the organism by eliminating the damaged cell [24] whilst GADD34 and its binding partner protein phosphatase-1 catalytic subunit (PP1c) are involved in eIF2 $\alpha$ de-phosphorylation that also modulates cell fate during protein translational stress. The activation of IRE-1 branch of UPR pathway leads to transcription induction of a subset of genes encoding protein degradation and pro-survival enzymes such as components of ER associated degradation (ERAD) including ER degradation-enhancing$\alpha$-mannosidase like protein (EDEM) [25-27]. Autoproteolytic activation of ATF- 6 stimulates transcription of genes encoding chaperones that assist in the refolding of misfolded proteins [28]. On balance, the UPR pathway in conjunction with ERAD controls the survival vs apoptosis decision of cells stressed by increased protein translation from external stimulus [29].

To circumvent the host cellular translational response, several viruses [respiratory syncytial virus, simian virus-5,
Tula virus, African swine fever virus, herpes simplex virus, cytomegalovirus, dengue virus and hepatitis C virus [30-34] have been shown to regulate UPR machinery. For example, in the case of hepatitis $\mathrm{C}$ virus, the virus encoded NS5A phosphoprotein, inhibits PKR activation by direct proteinprotein interaction [35]. Likewise, K3L gene product of vaccinia virus also binds to PERK and inhibits its activation [36]. Others such as herpes simplex viruses encode proteins that mimic host factors to regulate the protein synthesis traffic [37]. In light of these various mechanisms by which viruses modulate UPR pathway, we investigated the impact of CHIKV replication on the various components of the UPR machinery and compared it to another representative alphavirus, SINV, in order to reveal differential host responses to these unique but closely related pathogens. Real-time RT-PCR monitoring of transcriptional changes and Western blotting of infected cells were used to reveal the UPR components during both CHIKV and SINV infections. By carefully examining the UPR pathway components and by selectively inducing the ER stress using thapsigargin or tunicamycin treatment, we identified the suppression of eIF2 $\alpha$ phosphorylation during CHIKV infection in the early phase of virus replication that does not occur with SINV infection. Subsequently, transfection of individual CHIKVencoded proteins as GFP-fusion proteins revealed a mechanistic basis for the phenomenon dependent on nsP4.

\section{Materials and methods}

\section{Cells and viruses}

Mosquito cells Aedes albopictus clone (C6/36) and baby hamster kidney cells (BHK-21) were cultured in RPMI1640 medium (Gibco) supplemented with 10\% fetal bovine serum (FBS) (Gibco). Human embryonic kidney cells (HEK293) and human lung fibroblast cells (MRC-5) were cultured in DMEM (Gibco) supplemented with 10\% FBS. C6/36 cells were grown and maintained in $28^{\circ} \mathrm{C}$ temperature incubator. BHK-21, MRC-5 and HEK293 cells were grown and maintained at $37^{\circ} \mathrm{C}$ in a humidified incubator with $5 \% \mathrm{CO}_{2}$ atmosphere. CHIKV strain 'ROSS' and a laboratory strain of SINV MRM-39 strain (isolated in Australia [38]) was a generous gift from Dr. Ooi Eng Eong (Duke-NUS GMS). Both the viruses were amplified in C6/36 cells supplemented with $5 \% \mathrm{FBS}$ at $28^{\circ} \mathrm{C}$ and titrated by plaque assay as described previously [39]. Low passage number (below passage 5) was used for performing all experiments. Tunicamycin (Sigma) or thapsigargin (sigma) was used to induce UPR stress in the cells.

\section{In vitro virus quantification}

Prior to their use, plaque assays were carried out to quantify the number of infectious viral particles for CHIKV and SINV viruses used in the study. Briefly, BHK-21 cells were cultured to approximately $80 \%$ confluency in 24 -well plates 
(NUNC). The virus stock was 10-fold serially diluted from $10^{-1}$ to $10^{-12}$ in RPMI 1640 (Gibco). BHK-21 monolayers were infected with $200 \mu \mathrm{l}$ of each virus dilution. After incubation at $37^{\circ} \mathrm{C}$ and $5 \% \mathrm{CO}_{2}$ atmosphere for $1 \mathrm{~h}$ with rocking at $15 \mathrm{~min}$ intervals, the medium was decanted and $1 \mathrm{ml}$ of $1 \%(\mathrm{w} / \mathrm{v})$ carboxymethyl cellulose in RPMI supplemented with $2 \%$ FBS was added to each well. After $72 \mathrm{~h}$ of incubation at $37^{\circ} \mathrm{C}$ in $5 \% \mathrm{CO}_{2}$, the cells were fixed with $4 \%$ paraformaldehyde and stained for $30 \mathrm{~min}$ with $200 \mu \mathrm{l}$ of $1 \%$ crystal violet dissolved in $1 \mathrm{X}-\mathrm{PBS}$. After thorough rinsing with water, the plates were dried and the plaques were scored visually.

\section{Primer sequences used in the study}

Real-time PCR primer sequences: - CHIKV nsP1 (F-TAG AGCAGGAAATTGATCCC, R- CTTTAATCGCCTGGT GGTAT), SINV E1 (F-CACCCCGCACAAAAATGAC, RAAAAGGGCAAACAGCCAACTC), EDEM (F-TCATCC GAGTTCCAGAAAGCAGTC, R- TTGACATAGAGTGG AGGGTCTCCT), XBP-1 (F-TCACCCCTCCAGAACATC TC, R- ACTGGGTCCAAGTTGTCCAG), CHOP (F-TCT GATTGACCGAATGGTG, R- TCTGGGAAAGGTGGGT AGTG), BIP (F-TAGTGCAAGCTGAAGGCTGA, R- GG GCTGGAGTACAGTGGTGT), GADD34 (F-AACCTCTA CTTCTGCCTTGTCT, R- CGCCTCTCCTGAACGATAC TC), eIF2 $\alpha$ K2 (F-TTTGGACAAAGCTTCCAACC, R- AC TCCCTGCTTCTGACGGTA), 18s (F-TGTTCAAAGCAG GCCCGAG, R-CGGAACTACGACGGTATCTGATC), GA PDH (F- ACAGTCAGCCGCATCTTCTT, R- ACGACCA AATCCGTTGACTC), Actin (F-CAGGGGAACCGCTCA TTGCCAATGG, R-TCACCACACACTGTGCCCATCTA CGA), XBP-1 splicing (F- AAACAGAGTAGCAGCTCAG ACTGC, R- TCCTTCTGGGTAGACCTCTGGGAG).

CHIKV recombination cloning primer sequences: nsP1 (F- AGATCTCGAGCTCAAGCT TCGATGGAT CCTGTGTACGTG, R- TTAACCGTCGACTGCAGAT CCTGCACCCGCTCTGTC), nsP2 (F- TCCGGACTCA GATCTCGAGCTATAATAGAGACTCCGAGAGGA, R-GGATCCCGGGCCCGCGGTACCACATCCTGCTC GGGTGGC), nsP3 (F- TCCGGACTCAGATCTCGAGC TGCACCGTCGTACCGGGTA, R- GGATCCCGGGCC CGCGGTACCCCCACCTGCCCTGTCTAG), nsP4 (FTCCGGACTCAGATCTCGAGCTTATATAT

TCTCGTCGGAC, R- GGATCCCGGGCCCGCGGTAC CCTATTTAGGACCGCCGTA), Capsid (F- TCCGGA CTCAGATCTCGAGCTTGCATGAAAATCGAAAAT-

GAC, R- GGATCCCGGGCCCGCGGTACCCCACTCT TCGGCTCCCTC), E2 (F- AGATCTCGAGCTCAAGC TTCGCCATACTTAGCTCACTGT, R- TTATCTAGAT CCGGTGGATCCGCAGCATATTAGGCTAAG), E1 (FAGATCTCGAGCTCAAGCTTCGAGAACAGCTAAA GCGGCC, R- TTATCTAGATCCGGTGGATCCTTAG TGCCTGCTGAACGA).

\section{RNA extraction and real-time RT-PCR analysis}

HEK293 cells $\left(1 \times 10^{5}\right)$ were infected with virus (CHIKV/ SINV) at a multiplicity of infection (MOI) of 1 . At indicated time intervals, total RNA was isolated using the trizol (Invitrogen) extraction method and $1 \mu \mathrm{g}$ of total RNA was used for cDNA synthesis using ImProm II reverse transcription system (Promega), with oligo dT as primer. cDNA (50 ng) was used for real-time amplification of specific genes using respective primers (Materials and Methods) in Bio-Rad iQ-5 real time thermal cycler. The expression of viral and host gene products was normalized to Actin and GAPDH mRNA expression, followed by normalization to expression levels at uninfected conditions.

\section{XBP-1 splicing assay}

The XBP-1 splicing assay was performed essentially as described elsewhere [40]. Briefly, total RNA from the mock or virus (CHIKV/SINV) infected cells was extracted as described above and $1 \mu \mathrm{g}$ each of the total RNA was used for cDNA synthesis using ImProm II reverse transcription system (Promega), with oligo dT as primer, followed by PCR amplification of XBP-1 spliced genes using XBP-1 splicing specific primers (Materials and Methods). Amplified products were run on 2.5\% Agarose gel and visualized under UV ImageQuant.

\section{Western blotting}

HEK293 cells $\left(1 \times 10^{5}\right)$ were infected with MOI of 1 with CHIKV/SINV and total cell lysate was collected in NET lysis buffer (20 mM Tris, $100 \mathrm{mM} \mathrm{NaCl} \& 1 \mathrm{mM}$ EDTA) containing $0.1 \%$ Triton X-100 with protease inhibitor cocktail (Roche) at indicated time points post infections. After $30 \mathrm{~min}$ on ice, lysates were centrifuged at 13000 rpm for $10 \mathrm{~min}$ and supernatants were used to quantitate the amount of total protein by BCA assay (Pierce). Equal amount (2-5 $\mu \mathrm{g}$ each) of protein was loaded on $12 \%$ SDS PAGE followed by Western blotting. Blots were blocked overnight with blocking solution [2\% Fish gelatin (sigma) in $1 \mathrm{X} \mathrm{PBS}$ ] and were probed using primary antibodies against various proteins: GFP (Abcam), BIP (Abcam), ATF-6 (Abcam), HSP-90 (cell signaling), p58IPK (cell signaling), CHOP (cell signaling), phospho (Thr 980) PERK (cell signaling), eIF2 $\alpha$ (cell signaling) and phospho (Ser 51) eIF2 $\alpha$ (cell signaling). AntiGAPDH antibody (cell signaling) and anti-Actin antibody (sigma) were used as the loading control antibodies. All the antibodies used were diluted in blocking solution. After incubating with secondary HRPconjugated antibodies, blots were developed using ECL detection reagent (GE healthcare) and exposed on Amersham hyper films prior to development or visualized using Image-quant chemiluminiscent machine. 
Where required, image quantification was done using Image-J software.

\section{Construction of CHIKV-pEGFP clones}

Vector pEGFP-C1 (Clontech) was used to clone all the four non-structural (nsP1-4) and three major structural (C, E2 \& E1) genes of CHIKV. Briefly, CHIKV RNA was extracted using a viral RNA extraction kit (Qiagen). All the genes were amplified using gene specific primers (Materials and Methods) and superscript III one step RT PCR with platinum Taq kit (Invitrogen) in a thermal cycler (Applied Biosystem). Amplified genes were run on $1 \%$ agarose gel and amplicons were gel eluted using QIA-quick gel extraction kit (Qiagen). Individual purified PCR products were then inserted in to the pEGFP$\mathrm{C} 1$ vector using cloneEZ PCR cloning kit (Genscript) as per the manufacturer's recommendations. For convenience of restriction digestion analysis for screening positive clones, nsP1 was inserted in between HindIIIPstI restriction sites and nsP2-4 and $\mathrm{C}$ were cloned using Xhol-KpnI restriction sites. Similarly, E1 and E2 were cloned using HindIII-BamHI restriction sites. All the positive clones were further confirmed by DNA sequencing.

\section{Transfection of plasmids}

For transfection of plasmid DNA into HEK293 or MRC5 cells, cells were seeded to $70 \%$ confluency in a 24 well plate (Nunc) and incubated overnight in $37^{\circ} \mathrm{C}$ incubator supplemented with $5 \% \mathrm{CO}_{2}$ atmosphere. One $\mu \mathrm{g}$ of each of the plasmids (GFP vector, GFP-nsP1/2/3/4 or GFP-C/ E1/E2) was transfected using jet prime transfection reagent (Polypus BST scientific) as per the manufacturers described protocol. Transfected cells were incubated for $48 \mathrm{~h}$ for protein expression and then washed once with 1X-PBS (Gibco). Finally, cells were collected in TNETlysis buffer as described above and then subjected to Western blotting. The transfection efficiencies by fluorescence microscopic visualization for each of the plasmids except GFP-nsp2 were measured to be around $\sim 70 \%$ using polyplus jet prime transfection reagent, strictly as per the manufacturer's protocol. For GFPnsP2 transfection was done using $2 \mu \mathrm{g}$ of the plasmid and nearly $60 \%$ of transfection efficiency was achieved. No cytotoxicity was observed upon transfection of plasmids till $72 \mathrm{~h}$ post transfection. However, with GFPnsP2 some cytotoxicity (less than $20 \%$ cell death) was observed after $48 \mathrm{~h}$ post transfection.

\section{Immunofluorescence}

HEK293 cells were seeded on coverslips at a density of $1 \times 10^{5}$ cells/well in a 12-well plate. Following incubation for overnight at $37^{\circ} \mathrm{C}$ with $5 \% \mathrm{CO}_{2}$, the cells were infected with CHIKV or SINV at an MOI of 1 . At indicated time points after infection cells were fixed with ice cold $80 \%$ acetone for 10 min followed by overnight incubation with blocking buffer (5\% BSA in 1X PBS) at $4{ }^{\circ} \mathrm{C}$. The CHIKV RNA was detected using monoclonal dsRNA antibody (J2). The phosphorylated form of ER resident protein eIF $2 \alpha$ was detected using antibody against phospho (Ser 51) eIF2 $\alpha$ (cell signaling). Secondary antibodies used were anti-mouse alexa 488 and anti-rabbit alexa 594. All the antibodies used were diluted in blocking buffer. The coverslips were mounted on glass slides using prolong gold anti-fade mounting medium (Invitrogen) containing DAPI. Immunofluorescence images were captured using an inverted fluorescence microscope (Olympus IX71, USA) or upright confocal microscope (Zeiss) and image analysis was performed with Image-J software.

\section{Statistics}

Statistical comparison of results were performed using unpaired Student's $t$ test on the GraphPad Prism 5.0 software with $\mathrm{p}<0.005$ considered statistically significant.

\section{Results}

\section{Growth kinetics of CHIKV and SINV in vitro}

Since the study is primarily investigating CHIKV growth, we first determined the infectivity and growth kinetics of CHIKV in various cultured mammalian cell types in order to align our data with others in the field. Virus infection was achieved using MOI of 1 and at various time points post infection, growth kinetics was measured using standard plaque assay or by real time RT PCR for viral RNA detection. Mammalian mesenchymal cell types such as human lung fibroblast cells (MRC-5), human cervical epithelial cells (HeLa), human embryonic kidney cells (HEK293) and rat basophilic mast cell like cells (RBL-2H3) support prolific CHIKV replication reaching viral RNA induction up to $10^{4}$ fold in the infected cells (Figure 1A, B). However, several key immune cells like primary human peripheral blood mononuclear cells (PBMC) (data not shown), peripheral blood monocytic cells (THP-1 \& K562) and T lymphocytic cells (Jurkat) were found to be poorly infected with CHIKV, suggesting that immune cells may not be the primary targets for infection (Figure 1A). These findings are in agreement with previous reports that immune cells, including monocyte-derived macrophages and $\mathrm{T}$ and B cells are poorly susceptible to CHIKV infection $[41,42]$. Human embryonic kidney cells (HEK293) are widely used in the study of molecular pathways as they are robust with respect to transfection of foreign genes or proteins $[16,43,44]$. Indeed HEK293 cells supported CHIKV replication with plaque titers reaching $\sim 10^{11}$ $\mathrm{pfu} / \mathrm{ml}$ and up to 10,000-fold induction of viral RNA (Figure 1B). Equally, SINV growth in HEK293 cells under similar conditions was also robust with plaque 
assay titers of $\sim 10^{12} \mathrm{pfu} / \mathrm{ml}$ and nearly 100,000-fold induction of viral RNA (Figure $1 \mathrm{C}$ ). These high viral titers were also observed in other publications [45,46]. The similarity in growth kinetics of CHIKV \& SINV in HEK293 cells made this a relevant model for further investigation into the mechanism by which these viruses modulate the cellular UPR pathway to achieve the high viral load that is often observed in patients $[3,12,47]$.

\section{The ATF-6 signaling branch of UPR pathway during CHIKV} and SINV infection

Overload of viral protein translation in the ER during virus replication triggers the activation of the UPR pathways. We sought to investigate both the overall and specific impact of CHIKV and SINV replication on the UPR pathway by dissecting the individual signature branches of UPR: the ATF-6, IRE-1 and PERK. For this, HEK293 cells were infected with CHIKV or SINV at an MOI of 1 and at indicated time points $(0,3,6,12,24$ and $48 \mathrm{~h})$ post infection, cells were harvested, lysed and subjected to protein and RNA analysis for the component genes of ATF-6 pathway. We first confirmed by using immunofluorescence microscopy that majority of the cells were infected from $12 \mathrm{~h}$ post infection onwards, with $>95 \%$ staining positive for dsRNA for both CHIKV and SINV infections from $24 \mathrm{~h}$ post infection (Figure 2A). In response to ER stress BIP activates ATF-6 to autoproteolyse and induce the transcription of ER chaperone genes such as BIP, HSP-90 and p58IPK $[48,49]$. During CHIKV infection BIP was induced both at the transcriptional ( $\sim 12$ fold) and translational level ( $\sim 6$ fold) at $48 \mathrm{~h}$ post infection (Figure $2 \mathrm{~B}, \mathrm{D})$. The protein levels of both trans-membrane and cleaved cytosolic ATF-6 were increased throughout the infection time course compared to the uninfected control $(0 \mathrm{~h})$ (Figure $2 \mathrm{~B})$. The protein levels of ER chaperones, HSP-90 ( 2 fold) and p58IPK ( 1.5 fold) were also induced from $12 \mathrm{~h}$ post infection (Figure 2B), however, transcription levels were only induced at a statistically significant level (p-value less than 0.05$)$ at $24 \mathrm{~h}(\sim 2.5$ fold $)$ and $48 \mathrm{~h}$ ( 21fold) time points for $\mathrm{p} 58 \mathrm{IPK}$, and at $48 \mathrm{~h}(\sim 2$ fold $)$ for HSP90 (Figure 2D). In contrast to CHIKV, during SINV infection, no change in the protein levels of BIP was observed (Figure 2C), however the BIP transcript was significantly induced ( 22 fold $)$ at $48 \mathrm{~h}$ post infection (Figure 2E). No significant change was observed at the protein levels of both trans-membrane and cytosolic cleaved ATF-6 (Figure 2C). Also the protein levels of both HSP-90 and p58IPK were not significantly altered (Figure 2C). However, statistically significant induction of the transcripts for p58IPK (2, 16 fold) and HSP-90 (2.5, 16 fold) were observed at 24 and $48 \mathrm{~h}$ post infection (Figure 2E). Taken together, the data here suggest that the ATF-6 pathway signaling is significantly activated during CHIKV infection, whereas the SINV infection appears to not have a major modulatory effect on this branch of the UPR pathway.

\section{The IRE-1 signaling branch of UPR pathway during CHIKV and SINV infection}

Next the IRE1 branch was investigated by probing the splicing in the XBP-1 gene, which is a characteristic marker for activation of IRE-1 signaling [50-52]. The spliced XBP-1 gene product acts as transcription factor and activates the transcription of pro-survival genes such as EDEM and BCL-2 family proteins [53,54]. To assess the IRE-1 signaling, upon CHIKV/SINV infections, total RNA was extracted from the infected cells, harvested at various time points post infection and used for cDNA synthesis. The XBP-1 gene-splicing event was detected using a standard primer-based XBP-1 splicing assay [40]. For easier interpretation of data, the corresponding level of viral RNA present at each time point post infection was detected using virus gene specific detection primers
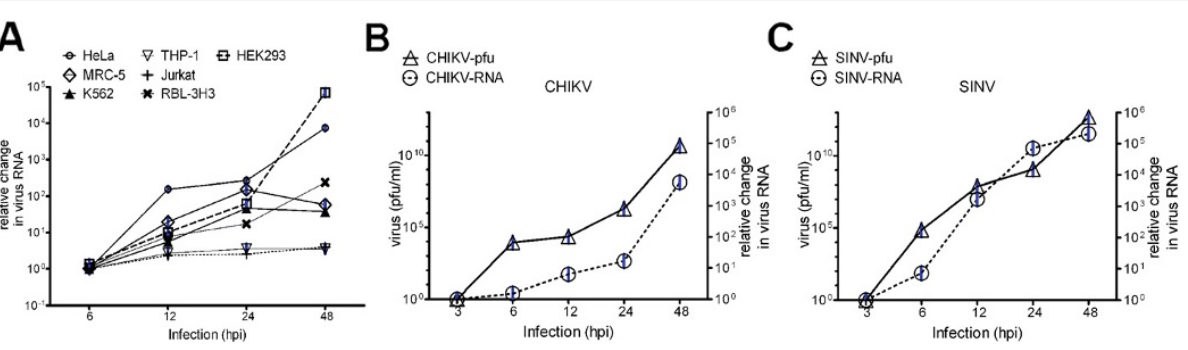

Figure 1 Growth kinetics of CHIKV and SINV in HEK293 cells. A) Real time RT-PCR analysis shows the growth kinetics of CHIKV in various cultured mammalian cell types and are presented as fold change in virus RNA (CHIKV nsP1 gene) over 6h infection time point using nsP1 specific primers (Materials and Methods) after normalization with Actin and GAPDH mRNA. The graph is representative of two independent repeats. B, C) HEK293 cells $\left(1 \times 10^{5}\right.$ cells) were infected with MOI-1 of CHIKV or SINV. At indicated time points post infection, infectious virus particles were quantified in the supernatant using standard plaque assay method (left Y-axis in the graph) and real time viral RNA quantification was done on the total RNA extracted from infected cells using specific primers (Materials and Methods) against nsP1 in CHIKV or E1 in SINV. Viral RNA is presented as fold change over $3 \mathrm{~h}$ infection time points after normalization with Actin and GAPDH mRNA (right Y-axis in the graph). The graphs are representative of three independent repeats. 
for CHIKV (nsP1 gene) and SINV (E1 gene) (Figure 3A, B). The data shows that CHIKV infection triggers moderate XBP-1 splicing from $12 \mathrm{~h}$ post infection, which only becomes prominent at $48 \mathrm{~h}$ post infection (Figure 3A). Quantitative real time PCR analysis showed that the transcription levels of both XBP-1 gene ( $~ 9$ fold) and EDEM-1 ( 16 fold) increased at $48 \mathrm{~h}$ post infection (Figure 3C). However in the case of SINV infection, the spliced XBP-1 gene transcript was much more prominent than was observed for CHIKV, starting from $12 \mathrm{~h}$ post infection with dramatic increase in the spliced product at 24 and $48 \mathrm{~h}$ post infection (Figure 3B). Real time PCR analysis revealed the increase in transcription of XBP-1 gene starting from $3 \mathrm{~h}$ post infection and significant increase in the EDEM transcript at $24 \mathrm{~h}(\sim 2.5$ fold) and $48 \mathrm{~h}$ ( 24 fold) post infection (Figure 3D).

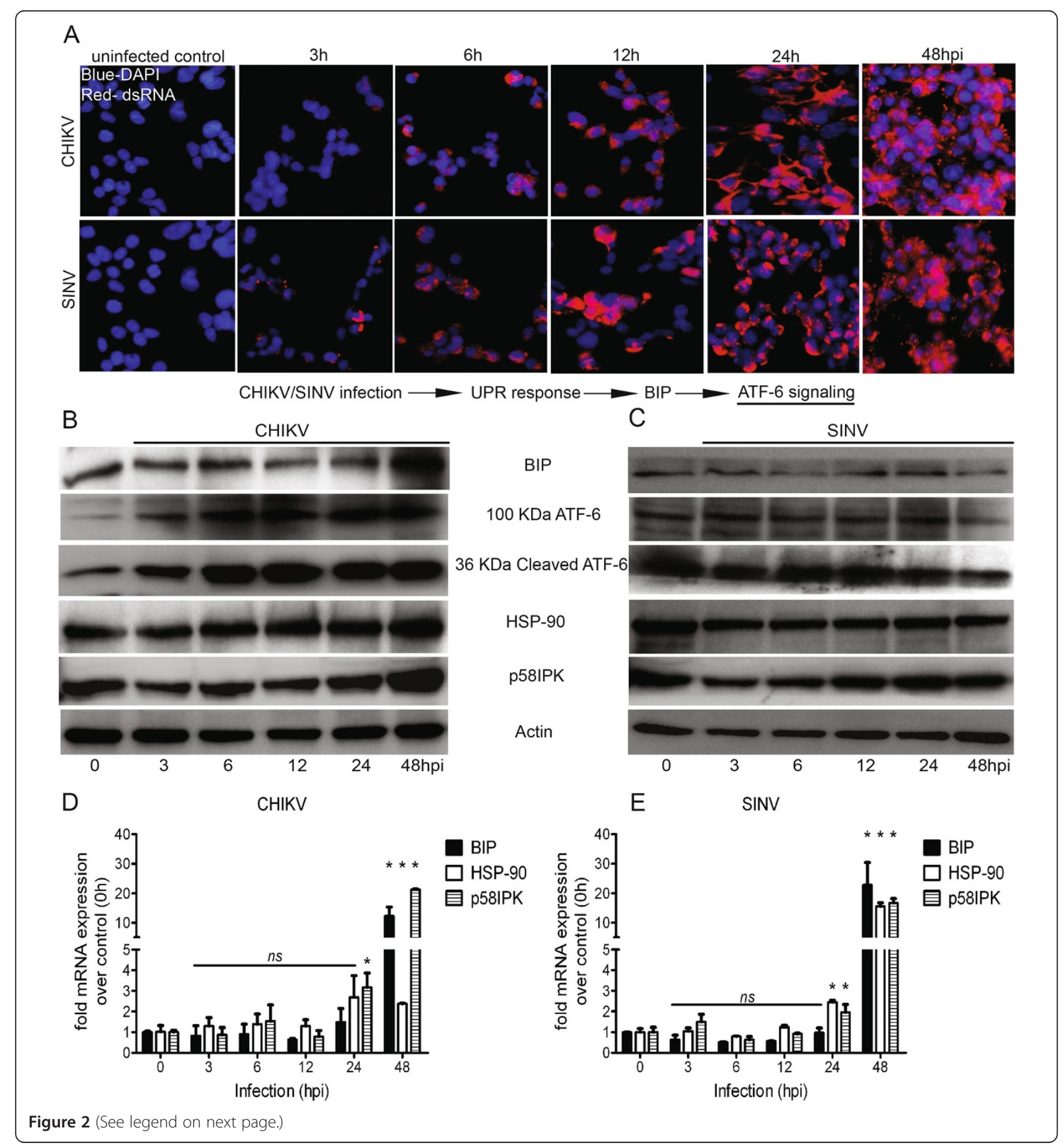


(See figure on previous page.)

Figure 2 The ATF-6 signaling during CHIKV and SINV infection. A) HEK293 cells ( $1 \times 10^{5}$ cells) were cultured on coverslips and either mock or $\mathrm{CHIKV/SINV} \mathrm{infected} \mathrm{at} \mathrm{an} \mathrm{MOI-1.} \mathrm{At} \mathrm{indicated} \mathrm{time} \mathrm{points} \mathrm{post} \mathrm{infection} \mathrm{cells} \mathrm{were} \mathrm{fixed} \mathrm{and} \mathrm{immunofluorescence} \mathrm{microscopy} \mathrm{was} \mathrm{performed} \mathrm{to}$ probe the virus replication-using antibody against dsRNA (red). Uninfected cells were used as negative control and nuclear stain DAPI (blue) was used as background control. From $12 \mathrm{~h}$ post infection onwards $\sim 90 \%$ of cells were infected with CHIKV/SINV and stained positive for dsRNA antibody. B, C) HEK293 cells ( $1 \times 10^{5}$ cells) were infected with MOI-1 of CHIKV/SINV and at indicated time points post infection cells were lysed using TNET lysis buffer. Lysed samples were run on 12\% SDS PAGE followed by Western blotting. Antibodies against BIP, ATF-6, HSP-90 and p58IPK were used to probe the ATF-6 pathway component protein levels during CHIKV/SINV infection. Anti-actin antibody was used to probe loading control and uninfected cells (Oh) were used as baseline protein level control. D, E) Under the similar experimental conditions and time points stated above, real time RT PCR analysis of BIP, HSP-90 and p58IPK transcripts was done on total RNA extracted from CHIKV/SINV infected cells using specific primers (Materials and Methods) against each of three genes. All three transcripts are presented as fold change over Oh (uninfected cells) after normalization with Actin and GAPDH mRNA. The graphs were plot using graph-pad prism software and are representative

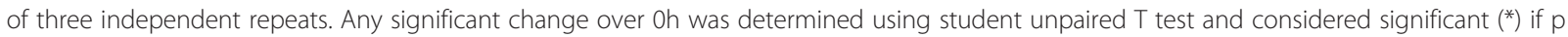
value was less than 0.05

Together the data suggests that both CHIKV and SINV activate the IRE-1 branch of UPR except that SINV infection appears to have a more profound impact on XBP-1 gene splicing from a very early time point.

\section{The PERK signaling branch of UPR pathway during CHIKV and SINV infection}

To examine the effects of CHIKV and SINV replication on the PERK pathway of UPR, antibodies against phsopho (thr 980) PERK and phospho (ser 51) eIF2 $\alpha$ were used to measure their respective phosphorylation levels. HEK293 cells were infected with CHIKV or SINV at an MOI of 1 and at $0,3,6,12,24$ and $48 \mathrm{~h}$ post infection cells were harvested and lysed before being subjected to protein and RNA analysis for PERK pathway component genes. During CHIKV infection the increase in the phosphorylation of PERK was detected starting from $12 \mathrm{~h}$ post infection (Figure 4A). Intriguingly, even when the PERK was activated (as indicated by its phosphorylation) no phosphorylation (ser 51) of eIF2 $\alpha$ was observed over total eIF $2 \alpha$ until $24 \mathrm{~h}$ post infection (Figure 4A). However, at $48 \mathrm{~h}$ post infection an increase in phosphorylation (ser 51) of eIF2 $\alpha$ was observed (Figure 4A) suggesting a delayed cellular response to virus infection and perhaps an implication for the possible role of virus mediated suppression of eIF $2 \alpha$ phosphorylation. Similar results were also obtained using another cell type MRC5 (Additional file 1: Figure S1) thus excluding the possibility that the delayed response is cell-type specific. The transcript level of eIF2 $\alpha \mathrm{K}$ was not altered during CHIKV infection (Figure 4C). Also, both the protein and transcript levels of downstream apoptosis marker, CHOP, were almost undetectable and not altered at any time points post CHIKV infection (Figure 4A, C). Interestingly, GADD34 a negative regulator of PERK was transcriptionally induced ( $\sim 9$ fold) at $48 \mathrm{~h}$ post infection (Figure 4C). However, during SINV infection the PERK signaling was in stark contrast to that observed for CHIKV infection (Figure 4). SINV infection induced phosphorylation of PERK (Figure 4B) and a dramatic increase in the phosphorylation (ser 51) of eIF2 $\alpha$ was observed over the entire time course, starting $3 \mathrm{~h}$ post infection (Figure 4B). Indeed, the transcript levels of eIF2 $\alpha$ k were also significantly elevated at $24(\sim 5$ fold $)$ and $48 \mathrm{~h}$ ( $\sim 12$ fold) post infection (Figure $4 \mathrm{D})$. CHOP activity was also dramatically increased during SINV infection at both the protein and transcript levels (upto 4 fold) starting $6 \mathrm{~h}$ post infection (Figure 4B, D). Overall, the data here suggest that CHIKV may modulate the PERK pathway signaling by suppressing the phosphorylation (ser 51) of eIF $2 \alpha$ in the early phase of infection (3$24 \mathrm{~h}$ ). SINV infection on the other hand leads to an uncontrolled UPR in the cell characterized by increased phosphorylation (ser 51) of eIF $2 \alpha$ and apoptosis.

\section{CHIKV infection suppress phosphorylation (ser 51) of elF2a}

To interrogate the delayed phosphorylation (ser 51) of eIF2 $\alpha$ during CHIKV infection, we first confirmed by immunofluorescence microscopy that the phosphorylation (ser 51) of eIF2 $\alpha$ at 24 h post infection was much more reduced and perhaps even suppressed in comparison to SINV or uninfected controls (Figure 5A). Next, we determined whether CHIKV infection could efficiently suppress phosphorylation (ser 51) of eIF2 $\alpha$ even in the presence of thapsigargin or tunicamycin (Figure 5B, Additional file 1: Figure S2A), the known chemical inducers of ER stress $[39,55,56]$. For this we verified that treatment of HEK293 cells with thapsigargin $(0.1 \mu \mathrm{M})$ or tunicamycin $(0.5 \mu \mathrm{g} / \mathrm{ml})$ for $6 \mathrm{~h}$ induced ER stress resulting in increased protein phosphorylation (ser 51) of eIF2 $\alpha$ (Figure 5B, Additional file 1: Figure S2A). Based on this thapsigargin/tunicamycin treatment time of $6 \mathrm{~h}$ was selected for further experiments to avoid any undesired toxicity effects of the drug. To examine the effect of CHIKV or SINV replication on thapsigargin/tunicamycin induced ER stress, HEK293 cells were infected with MOI of 1 of CHIKV or SINV for $12 \mathrm{~h}$ (for sufficient translation of virus encoded proteins), thoroughly washed twice with FCS free DMEM to remove any traces of excess virus and 


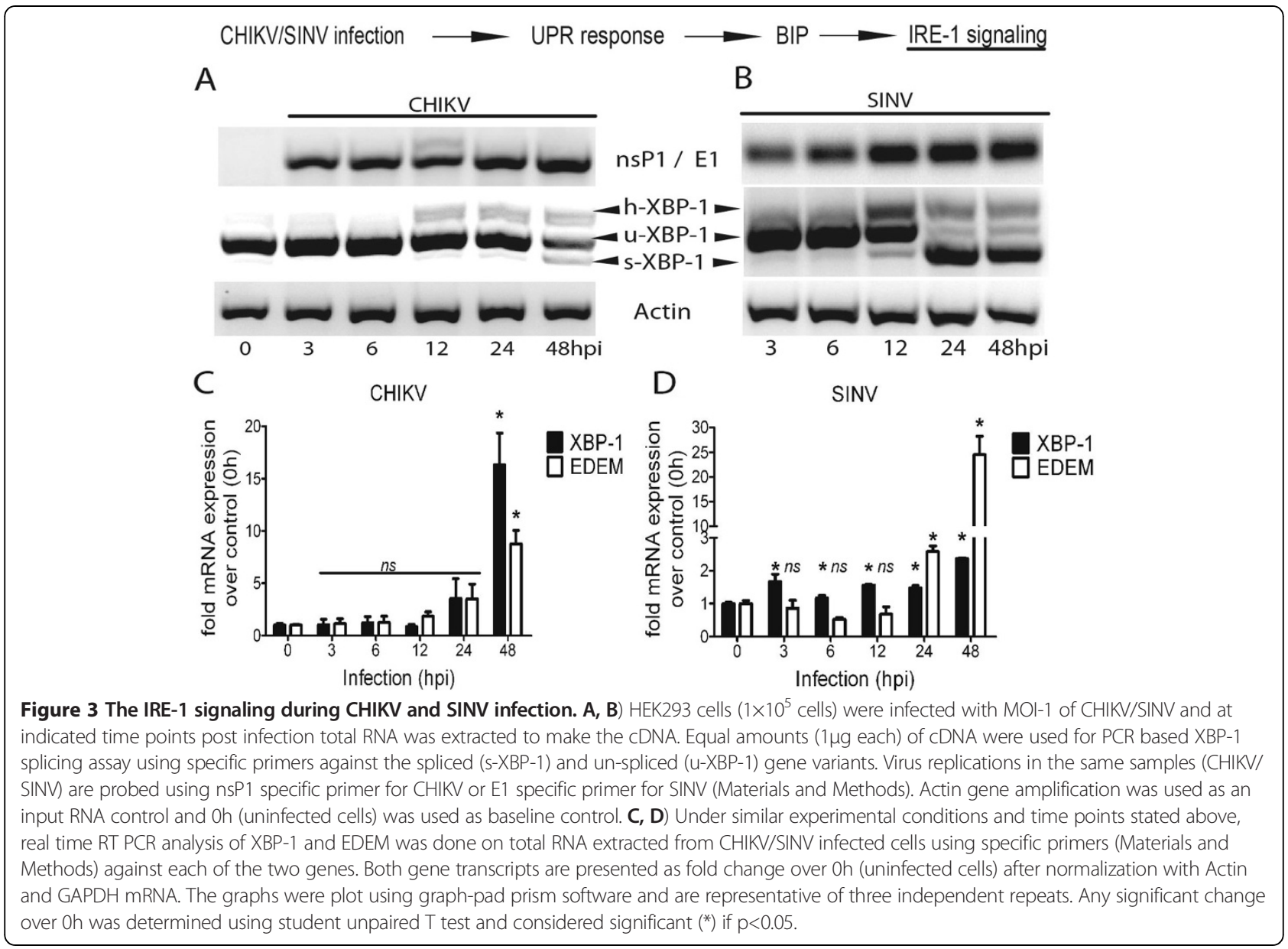

finally treated with thapsigargin $(0.1 \mu \mathrm{M}) /$ tunicamycin $(0.5 \mu \mathrm{g} / \mathrm{ml})$ or mock treatment for another $6 \mathrm{~h}$. The cells were harvested and lysed for Western blotting analysis and the media supernatants from the tests were used for virus quantification by plaque assay. As expected, the phosphorylation (ser 51) of eIF2 $\alpha$ was enhanced $(100 \%$ eIF $2 \alpha-P)$ over total eIF2 $\alpha$ in uninfected but thapsigargin or tunicamycin treated cells (Figure 5B, Additional file 1: Figure $\mathrm{S} 2 \mathrm{~A})$. At the same time dramatic reduction in the levels of eIF $2 \alpha$ (ser 51) phosphorylation $(\sim 8 \%$ eIF $2 \alpha-P$ ) over total eIF2 $\alpha$ was observed for cells infected only with CHIKV even in the presence of thapsigargin or tunicamycin (Figure 5B, Additional file 1: Figure S2A). However, SINV infection induced massive phosphorylation of eIF2 $\alpha$ in both mock and thapsigargin or tunicamycin treated cells (Figure 5B, Additional file 1: Figure S2A). Consistent with our earlier observation (see above in Figure 4, 5A) CHIKV infection by itself ( $\sim 5 \%$ eIF2 $\alpha-\mathrm{P})$ failed to phosphorylate (ser 51) eIF2 $\alpha$ (Figure 5B). Plaque assay data confirmed the significant reduction in both CHIKV and SINV viral titers upon treatment with thapsigargin for $6 \mathrm{~h}$ (Figure 5B). Next in order to examine if cellular phosphatases could be directly or indirectly modulating the de-phosphorylation of eIF $2 \alpha$ we used 'salubrinal' a specific inhibitor of ER phosphatase (PP1c) which function together with GADD34. For this, cells were infected with CHIKV/SINV at an MOI of 1 for $1 \mathrm{~h}$ followed by treatment with various concentrations of salubrinal starting from $0.625 \mu \mathrm{M}$ to $5 \mu \mathrm{M}$ for $24 \mathrm{~h}$. After $24 \mathrm{~h}$ post infection and treatment, media supernatant was collected for plaque assay and cells were collected for Western blotting analysis. By plaque assay, salubrinal treatment had no effect on the production of either CHIKV or SINV infectious virus particles. Nevertheless, salubrinal treatment lead to the increased phosphorylation of eIF2 $\alpha$ only in CHIKV infected cells suggesting the involvement of GADD34 in CHIKV mediated eIF2 $\alpha$ dephosphorylation (Figure 5C). In SINV infection salubrinal treatment had no significant increase in the phosphorylation of eIF2 $\alpha$ over untreated infected cells (Figure 5C).

\section{CHIKV protein nsP4 suppresses phosphorylation (Ser 51) of elF2a}

To understand mechanism by which CHIKV replication suppresses eIF2 $\alpha$ (Ser 51) phosphorylation and also to explore the possibility of whether any of the CHIKV- 

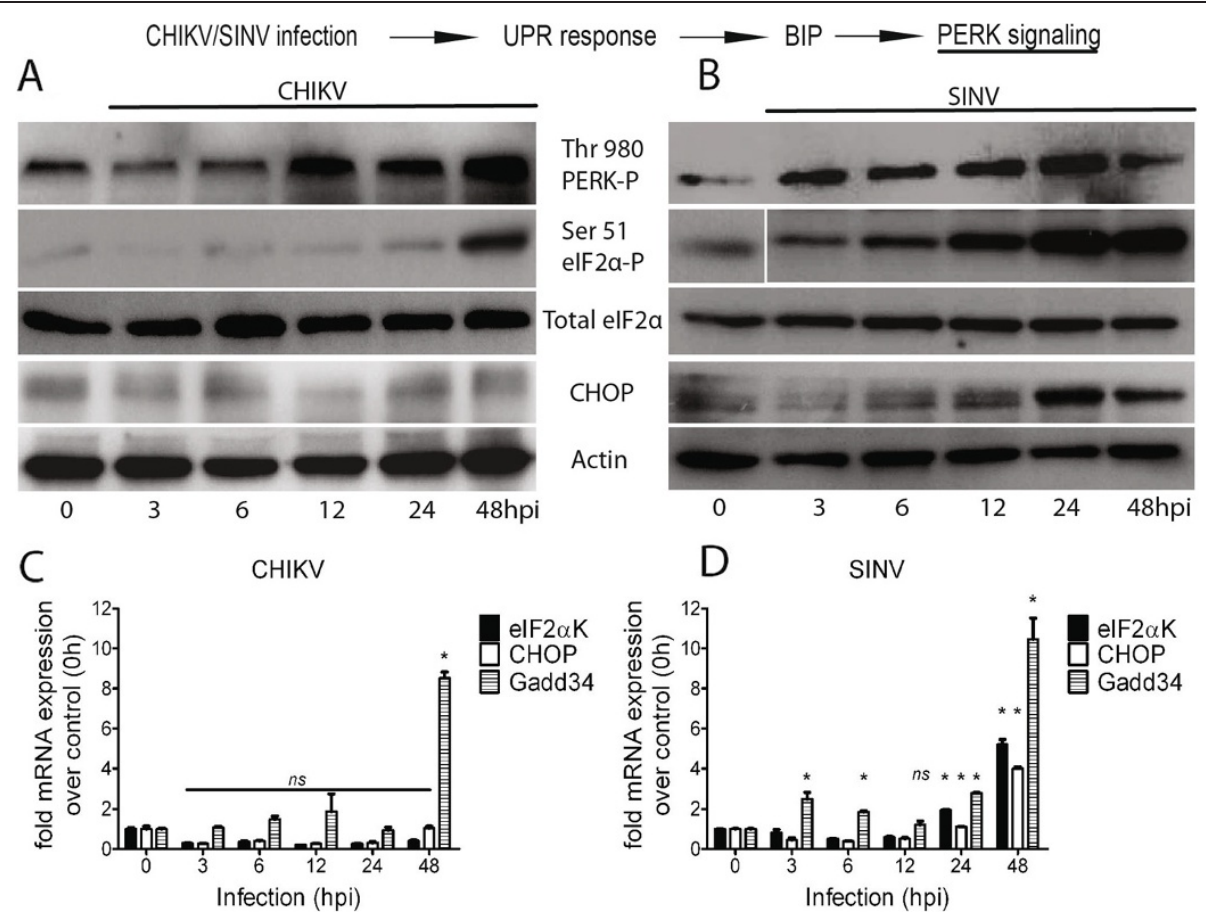

Figure 4 The PERK signaling during CHIKV and SINV infection. A, B) HEK293 cells ( $1 \times 10^{5}$ cells) were infected with MOI- 1 of CHIKV/SINV and at indicated time points post infection cells were lysed using TNET lysis buffer. Lysed samples were run on 12\% SDS PAGE followed by Western blotting. Antibodies against phospho (Thr 980) PERK, phospho (Ser 51) elF2a, elF2a and CHOP were used to probe the PERK pathway component protein levels during CHIKV/SINV infection. Anti-actin antibody was used to probe loading control and uninfected cells (Oh) were used as baseline protein level control. C, D) Under similar experimental conditions and time points stated above, real time RT PCR analysis of elF2aK, CHOP and GADD34 transcripts was done on total RNA extracted from CHIKV/SINV infected cells using specific primers (Materials and Methods) against each of three genes. All three transcripts are presented as fold change over Oh (uninfected cells) after normalization with Actin and GAPDH mRNA. The graphs were plot using graph-pad prism software and are representative of at-least three independent repeats. Any significant change over Oh was determined using student unpaired $T$ test and considered significant ${ }^{*}$ ) if $p<0.05$.

encoded proteins could play a role in this process, we individually cloned all the major structural and non structural genes (Figure 6A) into a CMV promoter driven GFP tagged vector. The primers listed in Materials and Methods were used to amplify the CHIKV genes from the cDNA obtained from viral RNA and the resulting correct size fragments were cloned into $\mathrm{pEGFP-C} 1$ vector by recombination cloning as described in the Materials and Methods section. The sequence verified clones (1 $\mu \mathrm{g}$ of each of the plasmid) were used to transfect HEK293 cells followed by incubation for $24 \mathrm{~h}$ to allow sufficient translation of plasmid-encoded proteins. SDS PAGE separation followed by Western blotting using anti-GFP antibody confirmed that GFP-fused CHIKV proteins were expressed and each migrated to the correct size (Figure 6B). In the case of GFP-E1 expression, three other bands were observed in addition to the expected size of $87 \mathrm{KDa}$ (Figure 6B). We speculate that being a surface glycoprotein, the higher band could be a multimeric form of GFP-E1, while the lower bands may be due to degradation product. To address the question whether any of these individually transfected CHIKV genes could suppress tunicamycin-induced eIF2 $\alpha$ (Ser 51) phosphorylation we transfected the individual GFPfused CHIKV genes in HEK293 cells followed by an incubation period of $24 \mathrm{~h}$ to allow the sufficient translation of cloned genes. This was followed by tunicamycin $(0.5 \mu \mathrm{g} / \mathrm{ml})$ treatment and further incubation for $24 \mathrm{~h}$ prior to fixing and visualizing using confocal immunofluorescence microscopy or harvesting cells and analysis by Western blotting. Remarkably, of the eight CHIKV gene constructs that were transfected, only the expression of CHIKV nsp4, which is the RNA-dependent-RNA polymerase, efficiently suppressed the phosphorylation (Ser 51) of eIF2 $\alpha$, even in the presence of tunicamycin (Figure 6C, D). However, other CHIKV proteins such as nsP1, nsP2, nsP3, C, E2, E1 and the control protein GFP had no effect on the phosphorylation (Ser 51) of eIF2 $\alpha$ (Figure 6C, D and other representative data which is not shown here. In order to negate the possibility that the nsP4 mediated suppression of the phosphorylation (Ser 51) of eIF $2 \alpha$ may be due to a cell-line artifact; CHIKVGFP constructs were also examined in MRC-5 fibroblast cell line. The results showed the similar trend of 


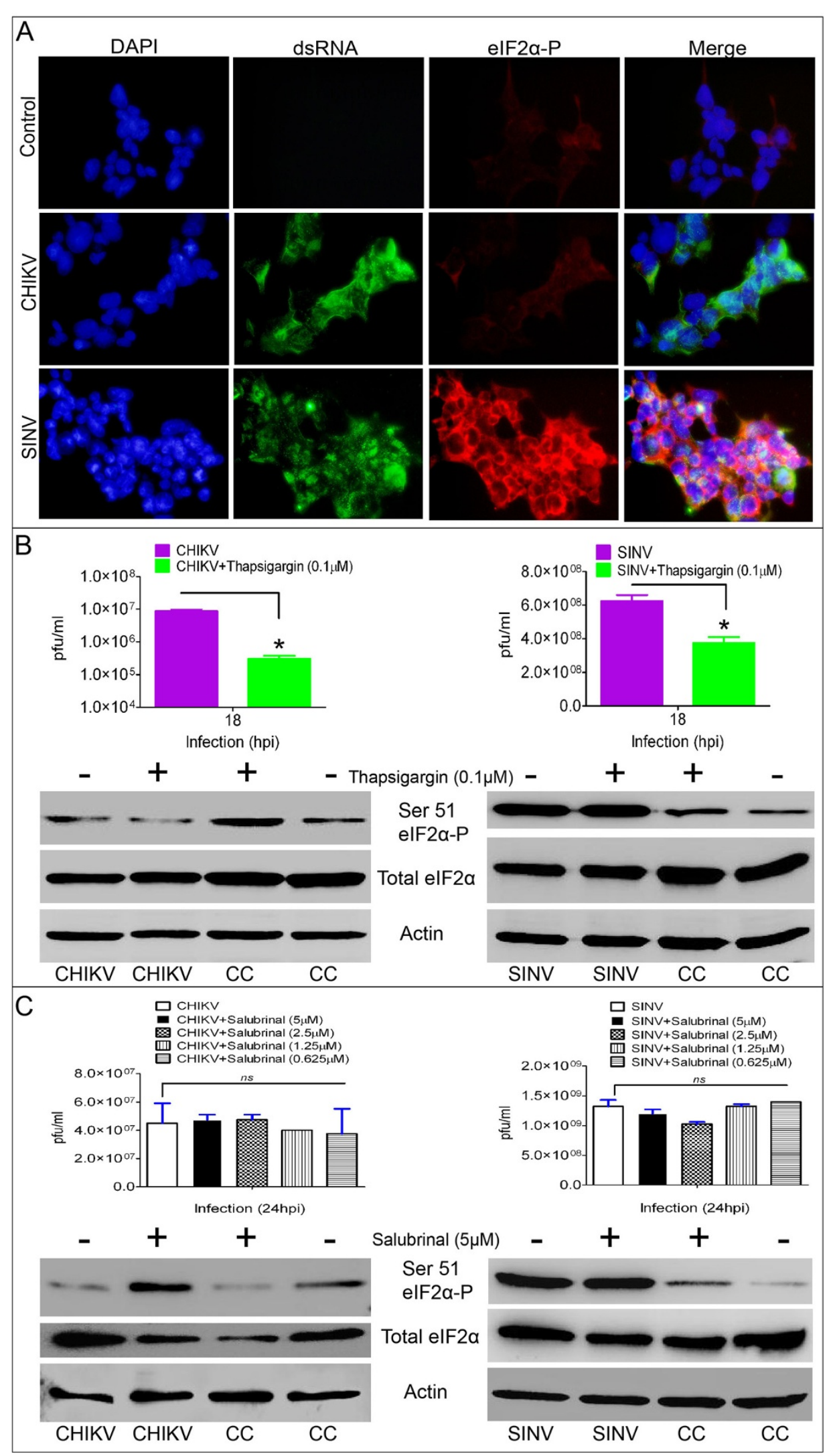

Figure $\mathbf{5}$ (See legend on next page.) 
(See figure on previous page.)

Figure 5 CHIKV infection suppresses the phosphorylation of elF2a. A) Immunofluorescence microscopy at 10X magnification on CHIKV/SINV (MOI-1) or mock-infected HEK293 cells at $24 \mathrm{~h}$. Unlike SINV, CHIKV infection failed to phosphorylate elf2a (red). Virus infection was probed using dsRNA antibody (green). B) HEK293 cells were mock or CHIKV/SINV infected (MOI-1) till 12h to allow the translation of CHIKV encoded proteins followed by treatment with thapsigargin $(0.1 \mu \mathrm{M})$ for $6 \mathrm{~h}$ and Western blotting was performed on cell lysates using specific antibodies against phospho (Ser 51) elF2a and elF2a. Anti-actin antibody was used to probe loading control and uninfected or untreated cells (CC) were used as baseline control. Plaque assay titers in the presence of thapsigargin for $6 \mathrm{~h}$ are presented as log pfu/ml. C) HEK293 cells were mock or CHIKV/SINV infected (MOI-1) for 1h. Cells were washed twice with 1X PBS to remove any traces of unbound virus particles followed by treatment with medium containing indicated concentrations of salubrinal for $24 \mathrm{~h}$. At $24 \mathrm{~h}$ media supernatant was used for plaque assay and cells were used for Western blotting using antibodies against phospho (Ser 51) elF2a and elF2a. Anti-actin antibody was used to probe loading control and uninfected or untreated cells (CC) were used as baseline control.

suppression of eIF2 $\alpha$ phosphorylation when MRC-5 cells were transfected with CHIKV nsP4 (Additional file 1: Figure S2B). Cumulatively, our data suggest that expression of CHIKV nsP4 significantly reduces the phosphorylation (Ser 51) of eIF $2 \alpha$ thus ensuring translation of viral proteins.

\section{Discussion}

Virus infection in mammalian cells consists of a series of events from entry to maturation and egress of virus. Remarkably, as intracellular parasites, viruses rely on the utilization of cellular machinery and resources to complete their life cycle. In this complex process, RNA viruses synthesize dsRNA intermediates and produce viral proteins within host cells. Consequently, viral replication elicits cellular responses, such as ER stress and the interferon response, as a first line of defense against the invading pathogen. To overcome this natural resistance, viruses have evolved various mechanisms to subvert host responses that limit or inhibit viral replication. Recently, several groups [44,57-59] have reported the impact of CHIKV or SINV replication on host cellular interferon and apoptotic machinery. In this study we specifically examined the cellular UPR signaling during CHIKV and SINV infections and show that the gene/ protein expression responses in the pathway are differentially modulated although the two viruses are considered to be closely related to each other. We explored in more detail the mechanistic basis for CHIKV modulation of the UPR pathway.

The stimulation of transcription and translation of BIP (the master regulator of UPR) has been observed for several viruses $[33,60]$. Not surprisingly the massive replication of CHIKV resulted in the induction of ER resident chaperones, such as BIP and HSP-90, which presumably assists in the folding of unfolded proteins in order to relieve the UPR stress within the cell. SINV infection, on the other hand, did not show significant induction in the expression of BIP and HSP-90, suggesting the possible early buildup of ER stress, which may contribute to the apoptosis and early cell death that was observed [61]. However SINV infection caused a more pronounced IRE-1 mediated splicing of XBP-1 gene that resulted in transcriptional induction of XBP-1 and EDEM, a prosurvival gene-product. Although the induction of XBP-1 and EDEM was less prominent during CHIKV infection in comparison to SINV infection, the present data is consistent with the recently reported role of IRE-1 signaling in delaying caspase-induced cell death [62]. In the PERK branch of UPR pathway, the phosphorylation of PERK was observed in both CHIKV and SINV infected cells but intriguingly the kinetics of the concomitant phosphorylation of eIF $2 \alpha$ showed marked difference between the two. At the early time points following CHIKV infection although increased PERK phosphorylation could be detected from $12 \mathrm{~h}$ post infection, the phosphorylation of eIF $2 \alpha$ was not detected until $48 \mathrm{~h}$ post infection whereas in SINV infected cells the eIF2 $\alpha$ phosphorylation could be detected from $3 \mathrm{~h}$ post infection. This discrepancy was addressed by treating CHIKV infected cells with thapsigargin or tunicamycin, the well known strong inducers of PERK and eIF $2 \alpha$ phosphorylation. This clearly demonstrated that eIF $2 \alpha$ phosphorylation in the cell was suppressed at the early stages of CHIKV infection (3-24 h) even with thapsigargin or tunicamycin treatment so as to allow high and sustained viral protein production without building up the ER stress. At $48 \mathrm{~h}$ post CHIKV infection the eIF $2 \alpha$ phosphorylation was quite prominent and comparable to the level observed at the same time point in SINV infected cells. However at this time point GADD34, a negative regulator of PERK, which mediates the de-phosphorylation of phospho-eIF2 $\alpha$ and p58IPK, a chaperone, which suppresses the PERK mediated phosphorylation of eIF $2 \alpha$ were also induced, suggesting that even when the cell tries to overcome its control by CHIKV infection, negative loop transcripts like GADD34 and $\mathrm{p} 58 \mathrm{IPK}$ are activated in order to rescue viral protein synthesis. To further explore the importance of GADD34 in mediating CHIKV induced suppression of eIF2 $\alpha$-phosphorylation we used a specific GADD34 inhibitor 'salubrinal'. Interestingly salubrinal treatment during CHIKV infection lead to an increased phosphorylation of eIF $2 \alpha$ suggesting the involvement of GADD34 in suppression of eIF2 $\alpha$-phosphorylation. Salubrinal treatment during SINV infection however did not show 


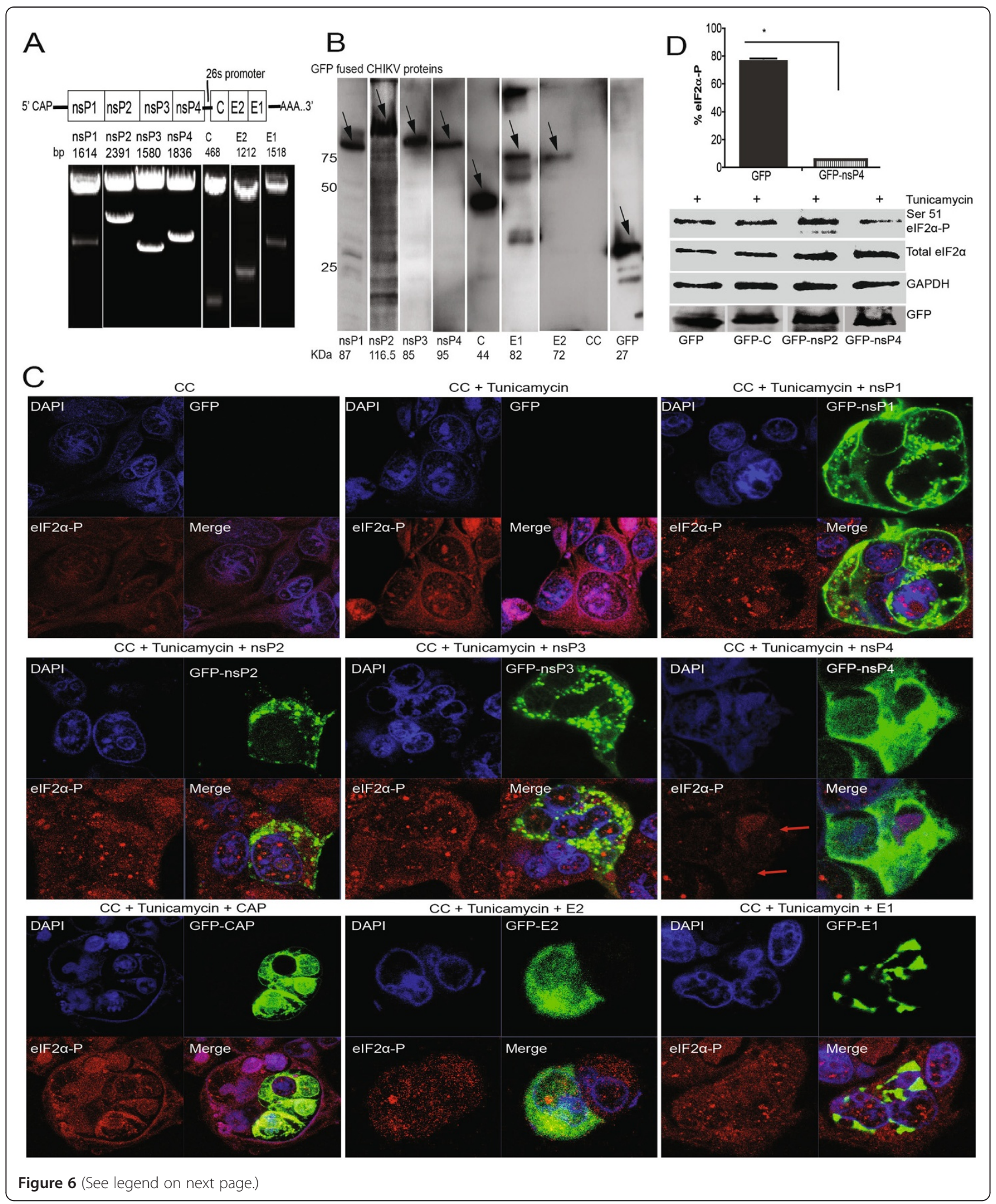




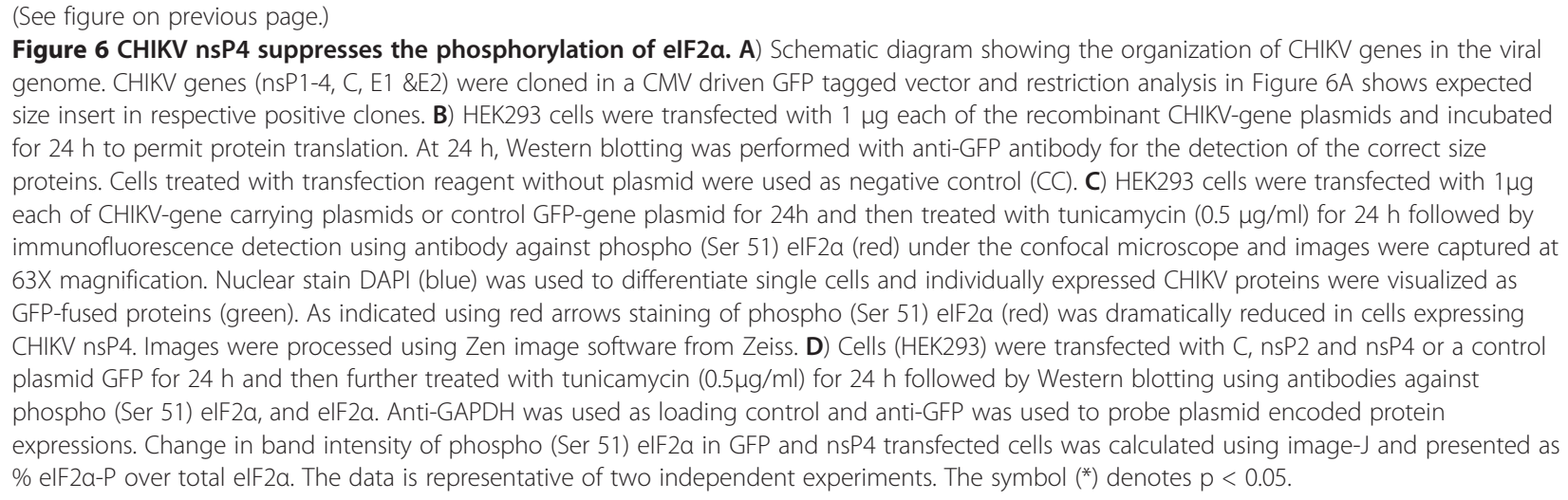

any significant change in the phosphorylation of eIF $2 \alpha$ over untreated SINV infected cells. Also, interestingly CHOP activity was not detected at both protein and transcription levels throughout the CHIKV infection time course. In stark contrast to CHIKV, SINV infection leads to phosphorylation of PERK and a dramatic increase in the phosphorylation of eIF $2 \alpha$ starting from $3 \mathrm{~h}$ post infection. The enhanced expression of CHOP detected as early as $3 \mathrm{~h}$ suggests the signature cell death by apoptosis during SINV infection. Although, GADD34 was transcriptionally induced during SINV infection the heightened phosphorylation of eIF $2 \alpha$ and further increase in CHOP activity triggers massive cell death, which could be observed starting from $12 \mathrm{~h}$ post infection (data not shown). Altogether, our data suggest that the PERK branch of UPR pathway is regulated during CHIKV infection as reflected by the suppression in the phosphorylation of eIF $2 \alpha$ during the early stage of infection and the reduced $\mathrm{CHOP}$ activity.

A mechanistic basis for the suppression in the phosphorylation of eIF $2 \alpha$ during the early stage of CHIKV infection was investigated using EGFP-tagged clones of seven CHIKV proteins and we discovered that the observed phenotype in the PERK pathway (i.e. suppression of the phosphorylation of eIF $2 \alpha$ ) is mediated by CHIKV nsP4 protein, which contains the RNAdependent-RNA polymerase activity. An interesting conjunction to our finding is that nsP4 protein of alphavirus is the first non-structural protein to be cleaved from the nsP1-4 polyprotein. and this cleavage as well as its enzymatic activity play a critical role in the synthesis of minus strand viral RNA [4]. Furthermore it is also well known that the alphavirus nsP4 is unstable, short-lived and degrades rapidly in the infected cell [63]. This instability of nsP4 could possibly explain why infected cells recover some degree of eIF $2 \alpha$ phosphorylation in the late phase of infection ( $48 \mathrm{~h}$ ). Together, we suspect that early suppression of the translation inhibition involving nsP4 could permit the buildup of template RNA for further translation and, thereby, support robust replication.

The question of how CHIKV regulates the host translational machinery to achieve a high level of replication is important to examine in detail particularly in light of seemingly contradictory reports on this topic. White et al. [59], reported independence of CHIKV induced translational shut-off from the phosphorylation of eIF $2 \alpha$, an intriguing finding since eIF2 $\alpha$ phosphorylation has a well established role in the shut-off of the host translational machinery [64]. However, in our detailed time course experiments with HEK293 cells, we did not observe eIF2 $\alpha$ phosphorylation until $48 \mathrm{~h}$ post infection, which was also consistently not observed in another cell type MRC-5 cells until $48 \mathrm{~h}$. We believe our detailed time course study provides advantage in understanding the complex early events of virus-host interactions in the UPR pathways. That it occurs, mechanistically, is interesting since the actions of transiently stable nsP4 function correlate to viral RNA replication and life cycle. Even at the late phase of infection induction of ER chaperones (BIP, HSP-90) along with pro-survival gene-product (EDEM) could work synergistically with negative regulators of eIF $2 \alpha$ phosphorylation (p58IPK, GADD34) to possibly support sustained CHIKV replication. SINV infection, on the contrary, is characterized by uncontrolled UPR as reflected by its failure to induce synthesis of ER chaperones followed by increased phosphorylation of eIF $2 \alpha$ and CHOP activity leading to early cell death. Since both CHIKV and SINV infections showed differential activation or modulation of the UPR, further detailed studies on the effects of infection on host cellular UPR machinery is required to better understand their characteristic prolific replication profiles.

In conclusion, we show that the two closely linked viruses CHIKV and SINV from the same family, responds differently to the host cellular UPR machinery. Indeed, CHIKV infection modulates the PERK branch of UPR machinery and that it occurs mechanistically through the involvement of the viral protein nsP4 in direct or 
indirect conjunction with host factors such as GADD34. The early suppression of UPR provides a mechanism for robust replication. Our observation opens up the possibility to explore in detail the interplay of CHIKV nsP4 protein in establishing the infection and exploit possible avenues to use this in identifying a suitable target for antiviral intervention.

\section{Additional file}

\section{Additional file 1: Supplementary_Material_Rathore et al.}

\section{Competing interests}

The authors declares that they have no competing interests.

\section{Authors' contributions}

AR carried out all the experiments and analysis reported in this manuscript. SV conceived the study. SV and MN participated in design and analysis of experiments together with AR and helped to draft the manuscript. All authors read and approved the final manuscript.

\section{Acknowledgements}

We thank Dr. Ooi Eng Eong for providing the laboratory strains of SINV. We also thank Drs. Shirish Shenolikar, Parmeen Akhtar, Ashley St. John and Nicole Moreland for critical reading of the manuscript and their discussions. This research in the SGV laboratory is supported by a DUKE-NUS Signature Research Program start-up grant funded by the Agency for Science,

Technology and Research, Singapore and the Ministry of Health, Singapore.

Received: 17 October 2012 Accepted: 11 January 2013

Published: 28 January 2013

\section{References}

1. Rulli NE, Melton J, Wilmes A, Ewart G, Mahalingam S: The molecular and cellular aspects of arthritis due to alphavirus infections: lesson learned from Ross River virus. Ann N Y Acad Sci 2007, 1102:96-108.

2. Powers $A M$, Logue $\mathrm{CH}$ : Changing patterns of chikungunya virus: reemergence of a zoonotic arbovirus. J Gen Virol 2007, 88:2363-2377.

3. Schwartz O, Albert ML: Biology and pathogenesis of chikungunya virus. Nat Rev Microbiol 2010, 8:491-500.

4. Strauss JH, Strauss EG: The alphaviruses: gene expression, replication, and evolution. Microbiol Rev 1994, 58:491-562.

5. Ross RW: The Newala epidemic. III. The virus: isolation, pathogenic properties and relationship to the epidemic. J Hyg (Lond) 1956, 54:177-191.

6. Taylor RM, Hurlbut HS, Work TH, Kingston JR, Frothingham TE: Sindbis virus: a newly recognized arthropodtransmitted virus. Am J Trop Med Hyg 1955, 4:844-862.

7. Brighton SW, Prozesky OW, de la Harpe AL: Chikungunya virus infection. A retrospective study of 107 cases. S Afr Med J 1983, 63:313-315

8. Borgherini G, Poubeau P, Jossaume A, Gouix A, Cotte L, Michault A, Arvin-Berod C, Paganin F: Persistent arthralgia associated with chikungunya virus: a study of 88 adult patients on reunion island. Clin Infect Dis 2008, 47:469-475.

9. Chhabra M, Mittal V, Bhattacharya D, Rana U, Lal S: Chikungunya fever: a re-emerging viral infection. Indian J Med Microbiol 2008 , 26:5-12.

10. Labadie K, Larcher T, Joubert C, Mannioui A, Delache B, Brochard P, Guigand L, Dubreil L, Lebon P, Verrier B, de Lamballerie X, Suhrbier A, Cherel Y, Le Grand R, Roques $P$ : Chikungunya disease in nonhuman primates involves long-term viral persistence in macrophages. J Clin Invest 2010, 120:894-906.

11. Mavalankar $D$, Shastri $P$, Raman $P$ : Chikungunya epidemic in India: a major public-health disaster. Lancet Infect Dis 2007, 7:306-307.

12. Hoarau JJ, Jaffar Bandjee MC, Krejbich Trotot P, Das T, Li-Pat-Yuen G, Dassa B, Denizot M, Guichard E, Ribera A, Henni T, Tallet F, Moiton MP, Gauzere BA, Bruniquet S, Jaffar Bandjee Z, Morbidelli P, Martigny G, Jolivet M, Gay F, Grandadam M, Tolou H, Vieillard V, Debre P, Autran B, Gasque P: Persistent chronic inflammation and infection by Chikungunya arthritogenic alphavirus in spite of a robust host immune response. J Immuno/ 2010, 184:5914-5927.

13. Levine B, Hardwick JM, Griffin DE: Persistence of alphaviruses in vertebrate hosts. Trends Microbiol 1994, 2:25-28.

14. Li L, Jose J, Xiang Y, Kuhn RJ, Rossmann MG: Structural changes of envelope proteins during alphavirus fusion. Nature 2010, 468:705-708.

15. Voss JE, Vaney MC, Duquerroy S, Vonrhein C, Girard-Blanc C, Crublet E, Thompson A, Bricogne G, Rey FA: Glycoprotein organization of Chikungunya virus particles revealed by X-ray crystallography. Nature 2010, 468:709-712.

16. Bourai M, Lucas-Hourani M, Gad HH, Drosten C, Jacob Y, Tafforeau L, Cassonnet $P$, Jones LM, Judith D, Couderc T, Lecuit M, Andre P, Kummerer BM, Lotteau V, Despres P, Tangy F, Vidalain PO: Mapping of Chikungunya Virus Interactions with Host Proteins Identified nsP2 as a Higly Connected Viral Component. J Virol 2012, 86:3121-3134.

17. Garmashova N, Gorchakov R, Volkova E, Paessler S, Frolova E, Frolov I: The Old World and New World alphaviruses use different virusspecific proteins for induction of transcriptional shutoff. J Virol 2007, 81:2472-2484.

18. Sawicki DL, Perri S, Polo JM, Sawicki SG: Role for nsP2 proteins in the cessation of alphavirus minus-strand synthesis by host cells. J Virol 2006, 80:360-371.

19. Toribio $R$, Ventoso I: Inhibition of host translation by virus infection in vivo. Proc Natl Acad Sci U S A 2010, 107:9837-9842.

20. van Steeg $H$, Kasperaitis M, Voorma HO, Benne R: Infection of neuroblastoma cells by Semliki Forest virus. The interference of viral capsid protein with the binding of host messenger RNAs into initiation complexes is the cause of the shut-off of host protein synthesis. Eur J Biochem 1984, 138:473-478.

21. Tardif KD, Waris G, Siddiqui A: Hepatitis C virus, ER stress, and oxidative stress. Trends Microbiol 2005, 13:159-163.

22. Bertolotti A, Zhang Y, Hendershot LM, Harding HP, Ron D: Dynamic interaction of BiP and ER stress transducers in the unfolded-protein response. Nat Cell Biol 2000, 2:326-332.

23. Novoa I, Zhang Y, Zeng H, Jungreis R, Harding HP, Ron D: Stress-induced gene expression requires programmed recovery from translational repression. EMBO J 2003, 22:1180-1187.

24. Oyadomari S, Araki E, Mori M: Endoplasmic reticulum stress-mediated apoptosis in pancreatic beta-cells. Apoptosis 2002, 7:335-345.

25. Kopito RR: ER quality control: the cytoplasmic connection. Cell 1997 88:427-430

26. Travers KJ, Patil CK, Wodicka L, Lockhart DJ, Weissman JS, Walter P: Functional and genomic analyses reveal an essential coordination between the unfolded protein response and ER-associated degradation. Cell 2000, 101:249-258.

27. Yoshida H, Matsui T, Hosokawa N, Kaufman RJ, Nagata K, Mori K: A timedependent phase shift in the mammalian unfolded protein response. Dev Cell 2003, 4:265-271.

28. Kozutsumi Y, Segal M, Normington K, Gething MJ, Sambrook J: The presence of malfolded proteins in the endoplasmic reticulum signals the induction of glucose-regulated proteins. Nature 1988, 332:462-464.

29. Harding HP, Calfon M, Urano F, Novoa I, Ron D: Transcriptional and translational control in the Mammalian unfolded protein response. Annu Rev Cell Dev Biol 2002, 18:575-599.

30. Bitko V, Barik S: An endoplasmic reticulum-specific stress-activated caspase (caspase-12) is implicated in the apoptosis of A549 epithelial cells by respiratory syncytial virus. J Cell Biochem 2001, 80:441-454.

31. Isler JA, Skalet AH, Alwine JC: Human cytomegalovirus infection activates and regulates the unfolded protein response. J Virol 2005, 79:6890-6899.

32. Netherton $\mathrm{CL}$, Parsley JC, Wileman T: African swine fever virus inhibits induction of the stress-induced proapoptotic transcription factor CHOP/ GADD153. J Virol 2004, 78:10825-10828.

33. Paradkar PN, Ooi EE, Hanson BJ, Gubler DJ, Vasudevan SG: Unfolded protein response (UPR) gene expression during antibody-dependent enhanced infection of cultured monocytes correlates with dengue disease severity. Biosci Rep 2011, 31:221-230.

34. Pena J, Harris E: Dengue virus modulates the unfolded protein response in a time-dependent manner. J Biol Chem 2011, 286:14226-14236.

35. Gale MJ Jr, Korth MJ, Tang NM, Tan SL, Hopkins DA, Dever TE, Polyak SJ, Gretch DR, Katze MG: Evidence that hepatitis $C$ virus resistance to 
interferon is mediated through repression of the PKR protein kinase by the nonstructural 5A protein. Virology 1997, 230:217-227.

36. Sood R, Porter AC, Ma K, Quilliam LA, Wek RC: Pancreatic eukaryotic initiation factor-2alpha kinase (PEK) homologues in humans, Drosophila melanogaster and Caenorhabditis elegans that mediate translational control in response to endoplasmic reticulum stress. Biochem J 2000, 346 Pt 2:281-293.

37. Cheng G, Feng Z, He B: Herpes simplex virus 1 infection activates the endoplasmic reticulum resident kinase PERK and mediates elF-2alpha dephosphorylation by the gamma(1)34.5 protein. J Virol 2005, 79:1379-1388

38. Doherty RL, Carley JG, Mackerras MJ, Marks EN: Studies of arthropod-borne virus infections in Queensland. III. Isolation and characterization of virus strains from wild-caught mosquitoes in North Queensland. Aust J Exp Biol Med Sci 1963, 41:17-39.

39. Rathore AP, Paradkar PN, Watanabe S, Tan KH, Sung C, Connolly JE, Low J, Ooi EE, Vasudevan SG: Celgosivir treatment misfolds dengue virus NS1 protein, induces cellular pro-survival genes and protects against lethal challenge mouse model. Antiviral Res 2011, 92:453-460.

40. Umareddy I, Pluquet O, Wang QY, Vasudevan SG, Chevet E, Gu F: Dengue virus serotype infection specifies the activation of the unfolded protein response. Virol J 2007, 4:91.

41. Solignat M, Gay B, Higgs S, Briant L, Devaux C: Replication cycle of chikungunya: a re-emerging arbovirus. Virology 2009, 393:183-197.

42. Sourisseau M, Schilte C, Casartelli N, Trouillet C, Guivel-Benhassine F, Rudnicka D, Sol-Foulon N, Le Roux K, Prevost MC, Fsihi H, Frenkiel MP, Blanchet F, Afonso PV, Ceccaldi PE, Ozden S, Gessain A, Schuffenecker I, Verhasselt B, Zamborlini A, Saib A, Rey FA, Arenzana-Seisdedos F, Despres P, Michault A, Albert ML, Schwartz O: Characterization of reemerging chikungunya virus. PLoS Pathog 2007, 3:e89.

43. Dhanushkodi NR, Mohankumar V, Raju R: Sindbis virus induced phosphorylation of IRF3 in human embryonic kidney cells is not dependent on mTOR. Innate Immun 2012, 18:325-332.

44. Krejbich-Trotot P, Gay B, Li-Pat-Yuen G, Hoarau JJ, Jaffar-Bandjee MC, Briant $L$, Gasque P, Denizot M: Chikungunya triggers an autophagic process which promotes viral replication. Virol J 2011, 8:432

45. Davis $J L$, Hodge $H M$, Campbell WE Jr: Growth of chikungunya virus in baby hamster kidney cell (BHK-21-clone 13) suspension cultures. Appl Microbiol 1971, 21:338-341.

46. Frolov I, Akhrymuk M, Akhrymuk I, Atasheva S, Frolova El: Early events in alphavirus replication determine the outcome of infection. J Virol 2012, 86:5055-5066.

47. Kurkela S, Manni T, Myllynen J, Vaheri A, Vapalahti O: Clinical and laboratory manifestations of Sindbis virus infection: prospective study, Finland, 2002-2003. J Infect Dis 2005, 191:1820-1829.

48. van Huizen R, Martindale JL, Gorospe M, Holbrook NJ: P58IPK, a novel endoplasmic reticulum stress-inducible protein and potential negative regulator of elF2alpha signaling. J Biol Chem 2003, 278:15558-15564.

49. Wang Y, Shen J, Arenzana N, Tirasophon W, Kaufman RJ, Prywes R: Activation of ATF6 and an ATF6 DNA binding site by the endoplasmic reticulum stress response. J Biol Chem 2000, 275:27013-27020.

50. Plongthongkum N, Kullawong N, Panyim S, Tirasophon W: Ire1 regulated XBP1 mRNA splicing is essential for the unfolded protein response (UPR) in Drosophila melanogaster. Biochem Biophys Res Commun 2007, 354:789-794.

51. Tardif KD, Mori K, Kaufman RJ, Siddiqui A: Hepatitis C virus suppresses the IRE1-XBP1 pathway of the unfolded protein response. J Biol Chem 2004, 279:17158-17164.

52. Yoshida H, Matsui T, Yamamoto A, Okada T, Mori K: XBP1 mRNA is induced by ATF 6 and spliced by IRE 1 in response to ER stress to produce a highly active transcription factor. Cell 2001, 107:881-891.

53. Lin JH, Li H, Yasumura D, Cohen HR, Zhang C, Panning B, Shokat KM, Lavail MM, Walter P: IRE1 signaling affects cell fate during the unfolded protein response. Science 2007, 318:944-949.

54. Molinari M, Calanca V, Galli C, Lucca P, Paganetti P: Role of EDEM in the release of misfolded glycoproteins from the calnexin cycle. Science 2003, 299:1397-1400.

55. Boyce M, Bryant KF, Jousse C, Long K, Harding HP, Scheuner D, Kaufman RJ, Ma D, Coen DM, Ron D, Yuan J: A selective inhibitor of elF2alpha dephosphorylation protects cells from ER stress. Science 2005, 307:935-939.
56. Oliver BL, Cronin CG, Zhang-Benoit Y, Goldring MB, Tanzer ML: Divergent stress responses to IL-1 beta, nitric oxide, and tunicamycin by chondrocytes. J Cell Physiol 2005, 204:45-50.

57. Fros JJ, Liu WJ, Prow NA, Geertsema C, Ligtenberg M, Vanlandingham DL, Schnettler E, Vlak JM, Suhrbier A, Khromykh AA, Pijlman GP: Chikungunya virus nonstructural protein 2 inhibits type I/II interferon-stimulated JAKSTAT signaling. J Virol 2010, 84:10877-10887.

58. Krejbich-Trotot P, Denizot M, Hoarau JJ, Jaffar-Bandjee MC, Das T, Gasque P: Chikungunya virus mobilizes the apoptotic machinery to invade host cell defenses. FASEB J 2011, 25:314-325.

59. White LK, Sali T, Alvarado D, Gatti E, Pierre P, Streblow D, Defilippis VR: Chikungunya virus induces IPS-1-dependent innate immune activation and protein kinase R-independent translational shutoff. J Virol 2011, 85:606-620

60. Buchkovich NJ, Yu Y, Pierciey FJ Jr, Alwine JC: Human cytomegalovirus induces the endoplasmic reticulum chaperone BiP through increased transcription and activation of translation by using the BiP internal ribosome entry site. J Virol 2010, 84:11479-11486.

61. Jan JT, Griffin DE: Induction of apoptosis by Sindbis virus occurs at cell entry and does not require virus replication. J Virol 1999, 73:10296-10302.

62. Joubert PE, Werneke SW, de la Calle C, Guivel-Benhassine F, Giodini A, Peduto L, Levine B, Schwartz O, Lenschow DJ, Albert ML: Chikungunya virus-induced autophagy delays caspase-dependent cell death. J Exp Med 2012, 209:1029-1047.

63. de Groot RJ, Rumenapf T, Kuhn RJ, Strauss EG, Strauss JH: Sindbis virus RNA polymerase is degraded by the $\mathrm{N}$-end rule pathway. Proc Natl Acad Sci U S A 1991, 88:8967-8971.

64. Sarre TF: The phosphorylation of eukaryotic initiation factor 2: a principle of translational control in mammalian cells. Biosystems 1989, 22:311-325.

doi:10.1186/1743-422X-10-36

Cite this article as: Rathore et al:: Differential unfolded protein response during Chikungunya and Sindbis virus infection: CHIKV nsP4 suppresses elF2a phosphorylation. Virology Journal 2013 10:36.

\section{Submit your next manuscript to BioMed Central and take full advantage of:}

- Convenient online submission

- Thorough peer review

- No space constraints or color figure charges

- Immediate publication on acceptance

- Inclusion in PubMed, CAS, Scopus and Google Scholar

- Research which is freely available for redistribution 